Supplement of Atmos. Chem. Phys., 18, 16601-16618, 2018

https://doi.org/10.5194/acp-18-16601-2018-supplement

(c) Author(s) 2018. This work is distributed under

the Creative Commons Attribution 4.0 License.

(c) (i)

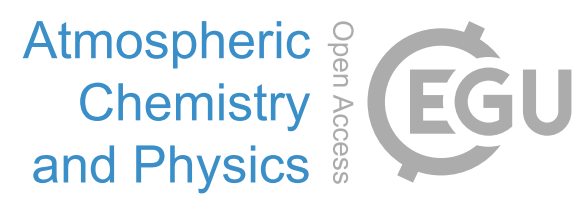

Supplement of

\title{
Vertical and horizontal distribution of regional new particle formation events in Madrid
}

Cristina Carnerero et al.

Correspondence to: Cristina Carnerero (cristina.carnerero@idaea.csic.es)

The copyright of individual parts of the supplement might differ from the CC BY 4.0 License. 
Among the 152 ions identified with the PTR-ToF-MS, only 3 exhibit temporal trends that might be relevant in the growth processes of NPF (Fig. S7). Two highly-oxygenated ions, $\mathrm{C}_{4} \mathrm{H}_{4} \mathrm{O}_{3} \mathrm{H}^{+}(\mathrm{m} / \mathrm{z}$ 101.023) and $\mathrm{C}_{2} \mathrm{H}_{4} \mathrm{O}_{3} \mathrm{H}^{+}\left(\mathrm{m} / \mathrm{z}\right.$ 77.023), and $\mathrm{NO}_{2}^{+}(\mathrm{m} / \mathrm{z}$ 45.9924) presented evolutions parallel to those of the particle diameter, i.e. the concentration of these ions increased simultaneously with the increase of particle diameter, and growth stopped when the concentration of the ions decreased (Fig. S9). This is observed also on days in which there is no particle formation but there is particle growth. Thus, the parent molecules of these ions are not linked to particle formation, but they would most probably contribute to particle growth. The fragment $\mathrm{C}_{4} \mathrm{H}_{4} \mathrm{O}_{3} \mathrm{H}^{+}$has, to the best of our knowledge, only been reported once over an orange grove in California (Park et al., 2013) and is most probably from secondary origin considering both its diurnal variation and oxidation state. It contains sufficient carbon atoms and oxygen functional groups to likely partition into the condensed phase. $\mathrm{NO}_{2}{ }^{+}$and $\mathrm{C}_{2} \mathrm{H}_{4} \mathrm{O}_{3}{ }^{+}$are known fragments of peroxyacetyl nitrate (PAN) (de Gouw et al., 2003), but $\mathrm{NO}_{2}{ }^{+}$can also arise from the fragmentation of a wide range of peroxynitrates $\left(\mathrm{ROONO}_{2}\right)$ or alkyl and multifunctional nitrates $\left(\mathrm{RONO}_{2}\right)$ (Aoki et al., 2017; Duncianu et al., 2017). While the uptake of PAN on particles can be considered as negligible (Roberts, 2005), higher molecular weight organonitrates are more likely to partition onto the particle phase. Thus, the particles growth appears to be driven by the uptake of secondary organic compounds. More precisely, in an urban atmosphere such as Madrid characterized by high $\mathrm{NO}_{2}$ concentrations, the formation of organonitrates and/or peroxynitrates could play an important role in the particle growth processes. We cannot prove this assumption using the PTR-ToF-MS measurements. We cannot check if the growth rates can be explained by sulfuric acid alone, since $\mathrm{SO}_{2}$ levels were below the detection limit of the standard air quality UV spectrometry instruments during all the period.

\section{References}

Aoki, N., Inomata, S., and Tanimoto, H.: Detection of C1-C5 alkyl nitrates by proton transfer reaction timeof-flight mass spectrometry, Int. J. Mass Spectrom., 263, 12-21, 2007.

de Gouw, J.A., Goldan, P.D., Warneke, C., Kuster, W.C., Roberts, J.M., Marchewka, M., Bertman, S.B., Pszenny, A.A.P., Keene, W.C: Validation of proton transfer reaction-mass spectrometry (PTR-MS) measurements of gas-phase organic compounds in the atmosphere during the New England air quality study (NEAQS) in 2002, J. Geophys. Res. Atmos. 108 (D21), 2003.

Duncianu, M., David, M., Kartigueyane, S., Cirtog, M., Doussin, J-F., Picquet-Varrault, B.: Measurement of alkyl and multifunctional organic nitrates by proton-transfer-reaction mass spectrometry, Atmospheric Measurement Techniques, 10 (4), 1445-1463, 2017. 
Table S1: Summary of shrinkage events showing the starting time, considered as the moment of first detection of a decrease in size, the final time, shrinking rate (SR) and geometric mean diameters at the beginning and end of the process. It is noted that on some days more than one shrinkage process is observed and all SR are shown.

\begin{tabular}{ccccccc} 
& \multicolumn{2}{c}{$\mathrm{SR}_{\mathrm{Dp}<40 \mathrm{~nm}}\left(\mathrm{~nm} \mathrm{~h}^{-1}\right)$} & \multicolumn{2}{c}{$\mathrm{SR}_{\text {Aitk, } \mathrm{Dp}>40 \mathrm{~nm}}\left(\mathrm{~nm} \mathrm{~h}^{-1}\right)$} \\
Date & CSIC & CIEMAT & ISCIII & CSIC & CIEMAT & ISCIII \\
\hline $03 / 07 / 2016$ & & & & & -1.7 \\
$12 / 07 / 2016$ & -8.3 & & -5.4 & -7 & -9 \\
$13 / 07 / 2016$ & $-7.9,-5.5$ & & & & -4.9 \\
$14 / 07 / 2016$ & & & & $-20.5,-6.3$ & -11.9 \\
$15 / 07 / 2016$ & & -1.9 & & & \\
$16 / 07 / 2016$ & & -1.9 & & & \\
$17 / 07 / 2016$ & & & -1.5 & & \\
$18 / 07 / 2016$ & & -2.2 & -3.6 & & \\
$19 / 07 / 2016$ & & & & & \\
\hline
\end{tabular}
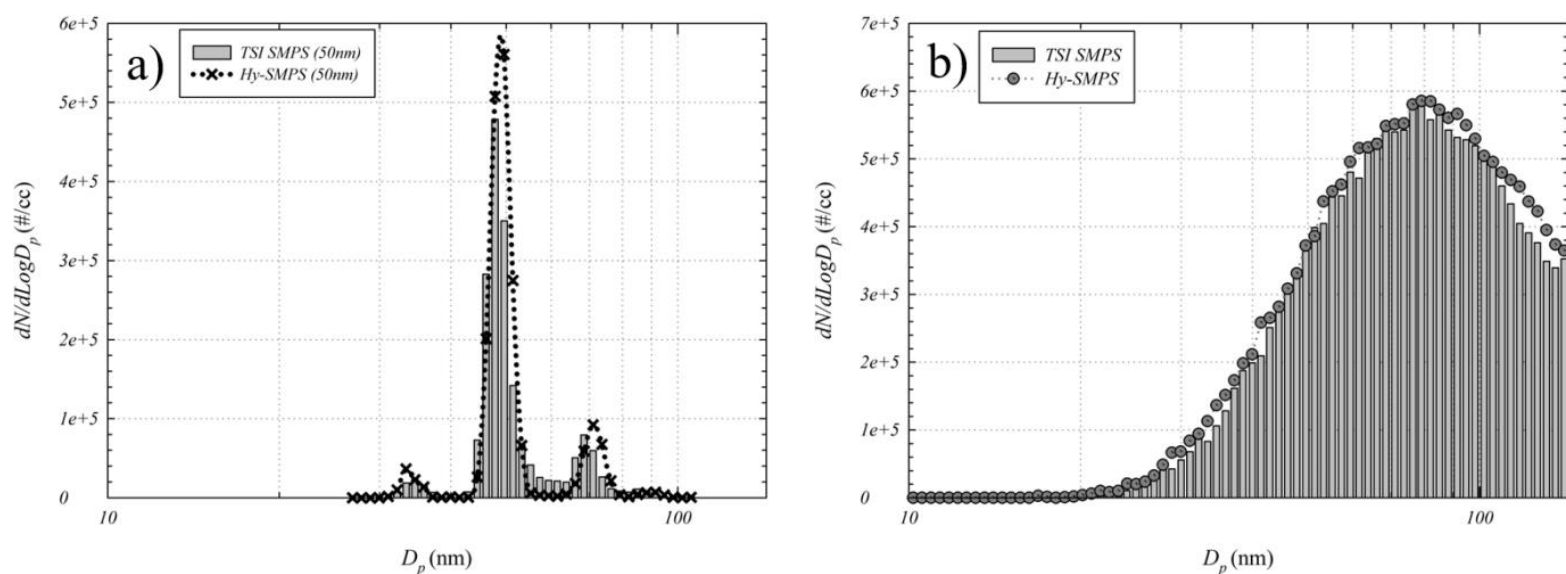

Figure S1: a) Intercomparison between TSI-SMPS and Hy-SMPS for $50 \mathrm{~nm}$ monodisperse NaCl particles. The major peak shows $50 \mathrm{~nm}$ particle and the 2 minor peaks are the doubly charged particles. b) Polydisperse aerosol size distribution intercomparison between TSI-SMPS and Hy-SMPS. 

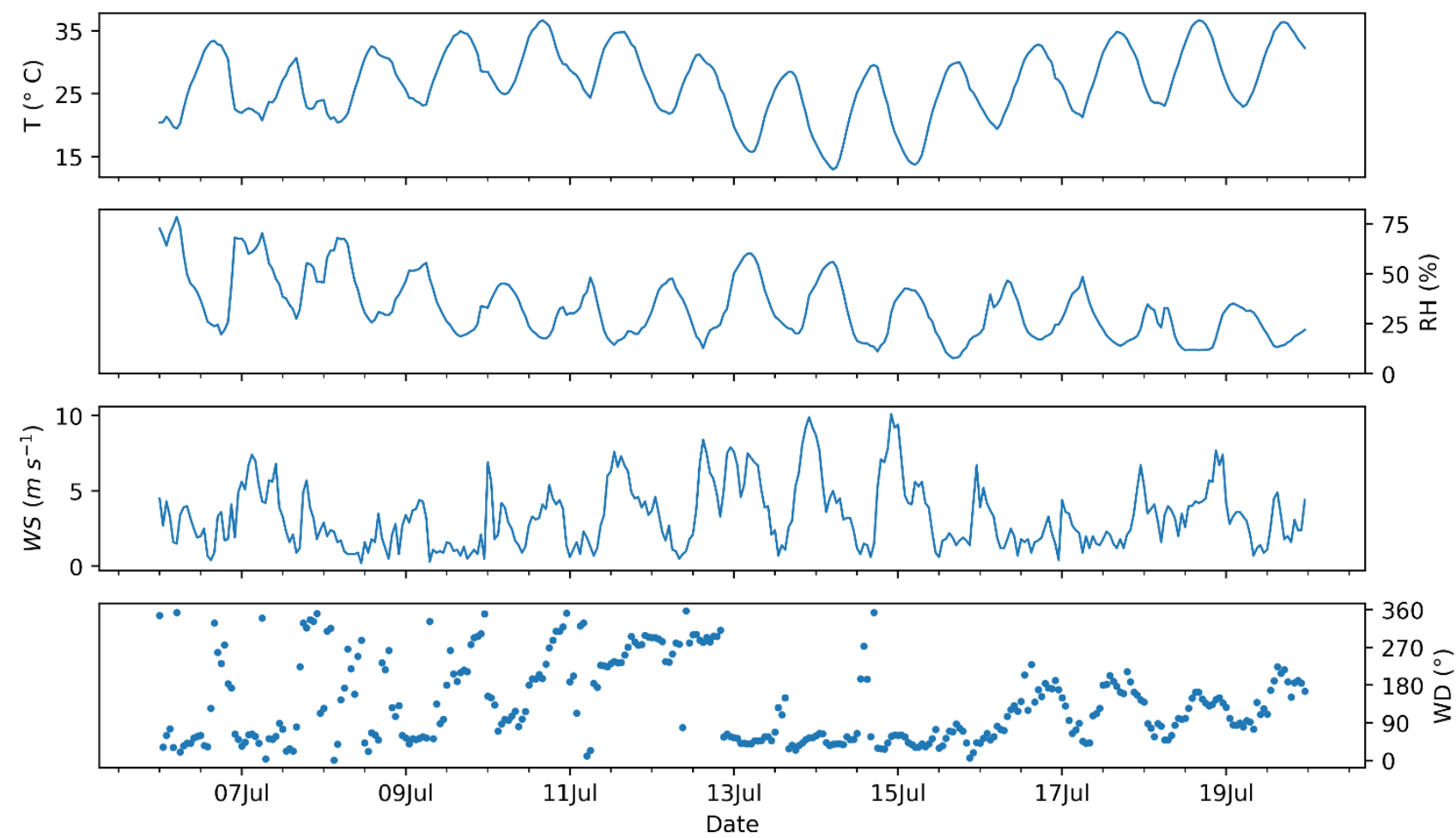

Figure S2: Temperature, relative humidity, wind speed and wind direction measured at the CIEMAT meteorological tower from 6 to 20 July 2016. Temperature and relative humidity are measured at $4 \mathrm{~m}$, and the anemometer is located at $55 \mathrm{~m}$. Time is UTC, local time is UTC +2 . 

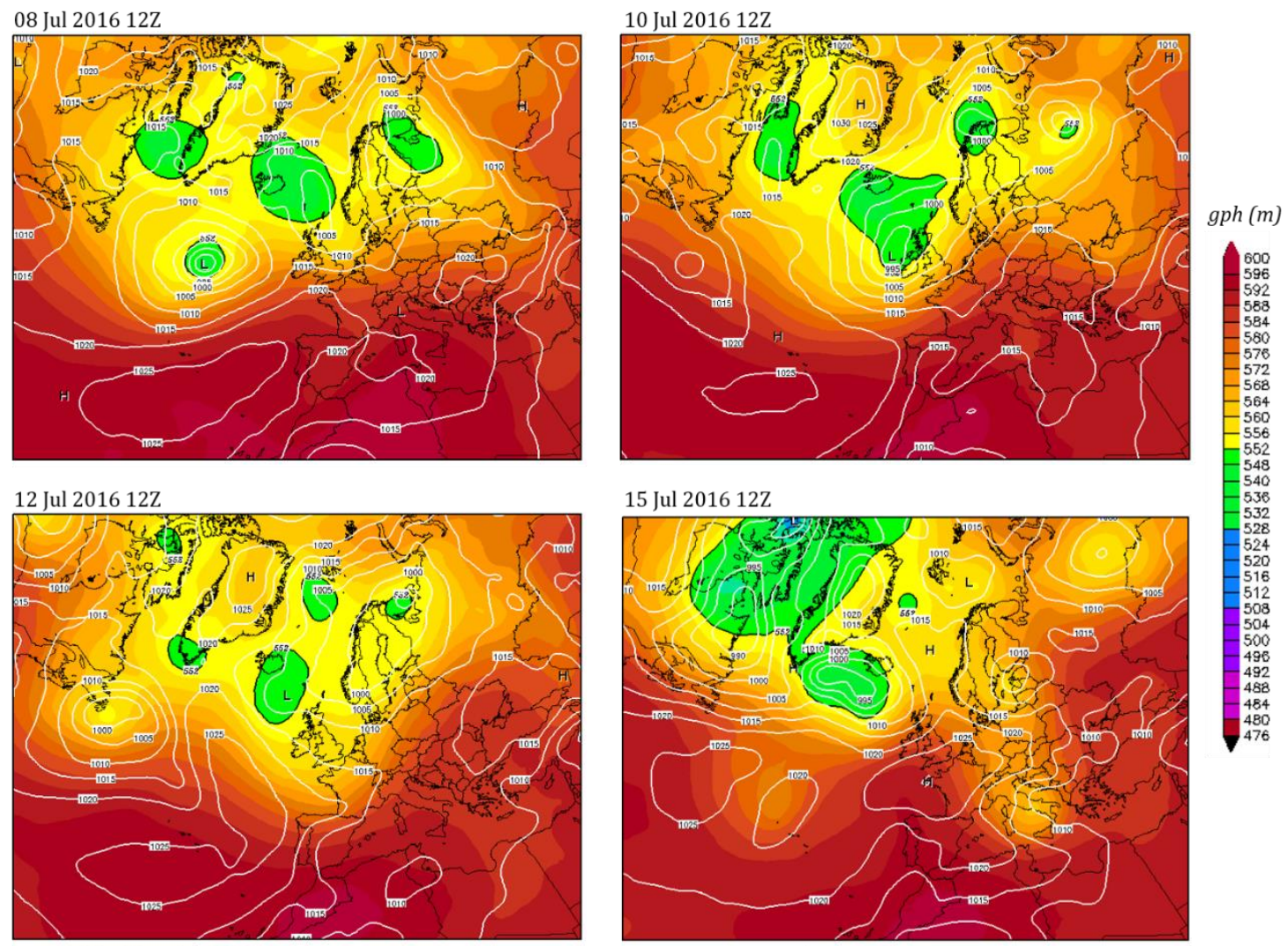

Figure S3: $500 \mathrm{hPa}$ geopotential height, in $\mathrm{m}$, and mean sea level pressure in $\mathrm{hPa}$ obtained from the Climate Forecast System reanalysis. The maps correspond to 8, 10, 12 and 15 July 2016, at 12:00 UTC.
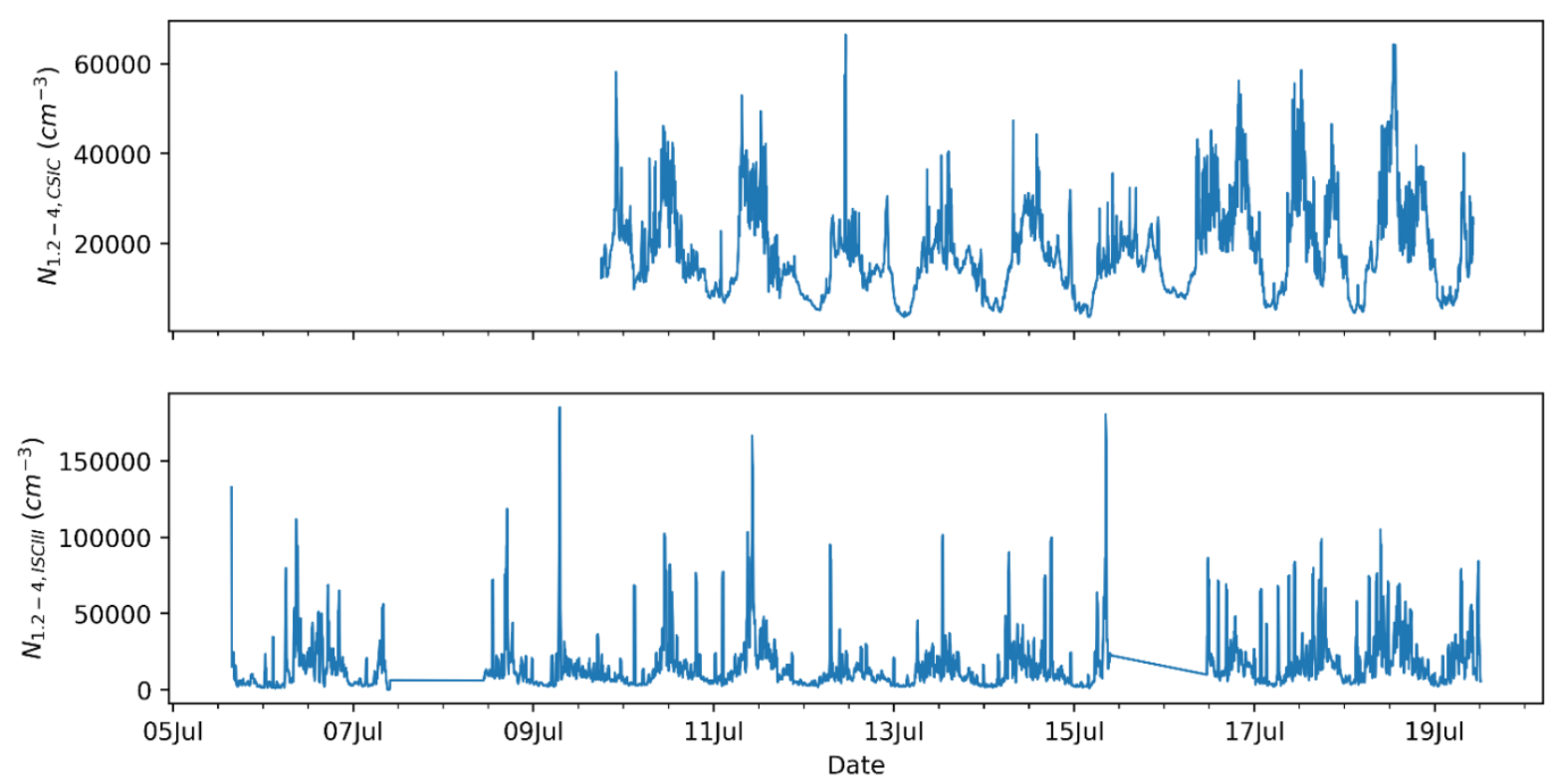

Figure S4: Concentrations of $1.2-4 \mathrm{~nm}$ particles measured from 6 to 20 July at CSIC and ISCIII. 
2016-07-12
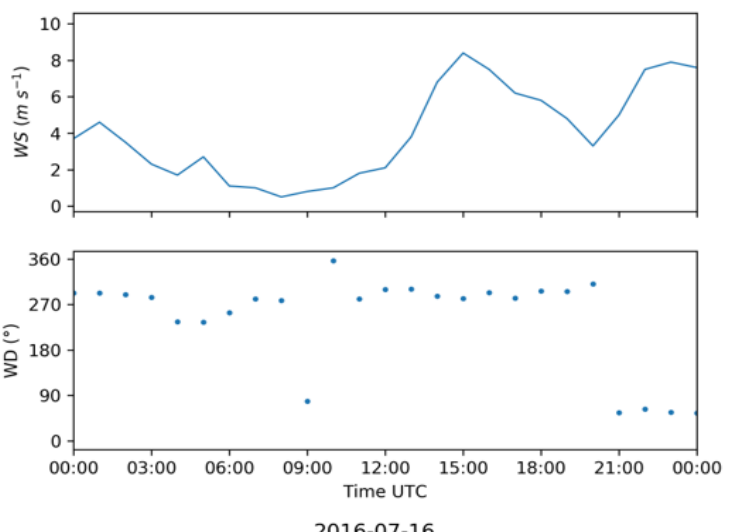

2016-07-16
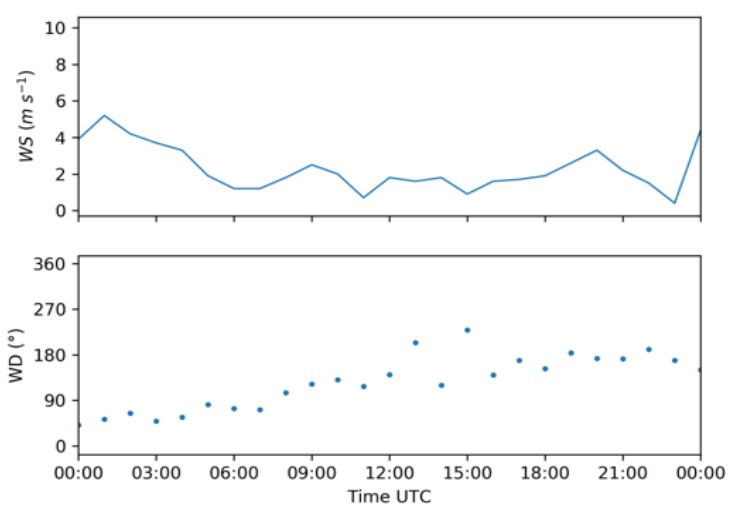

2016-07-13
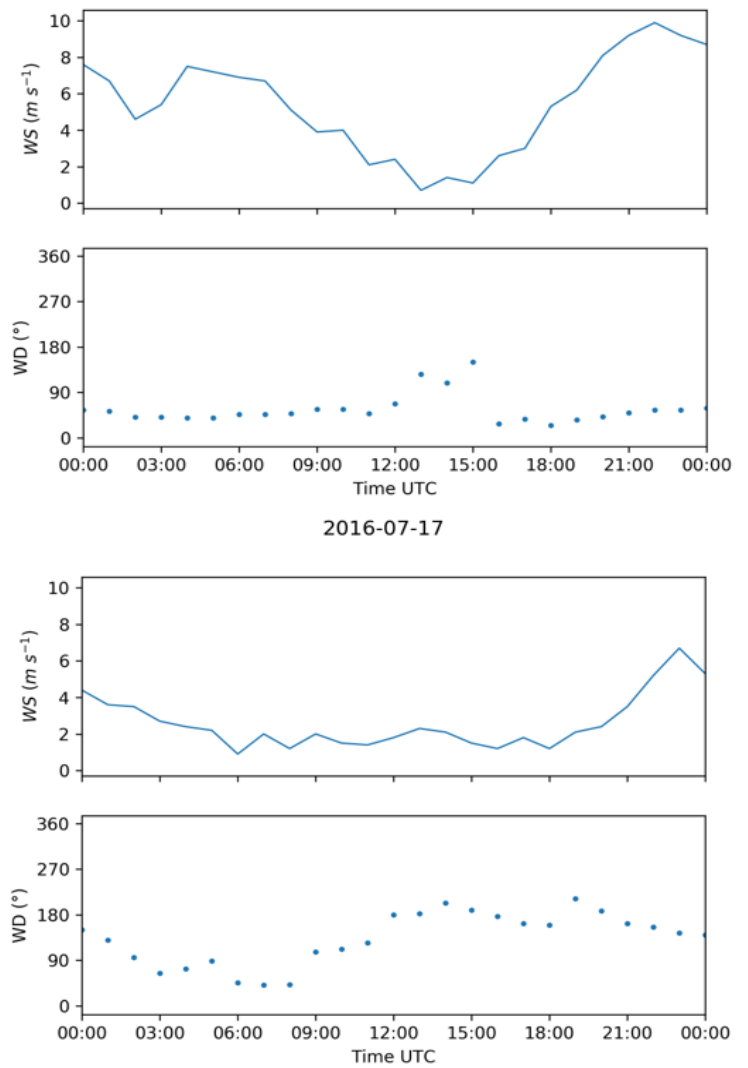

2016-07-14
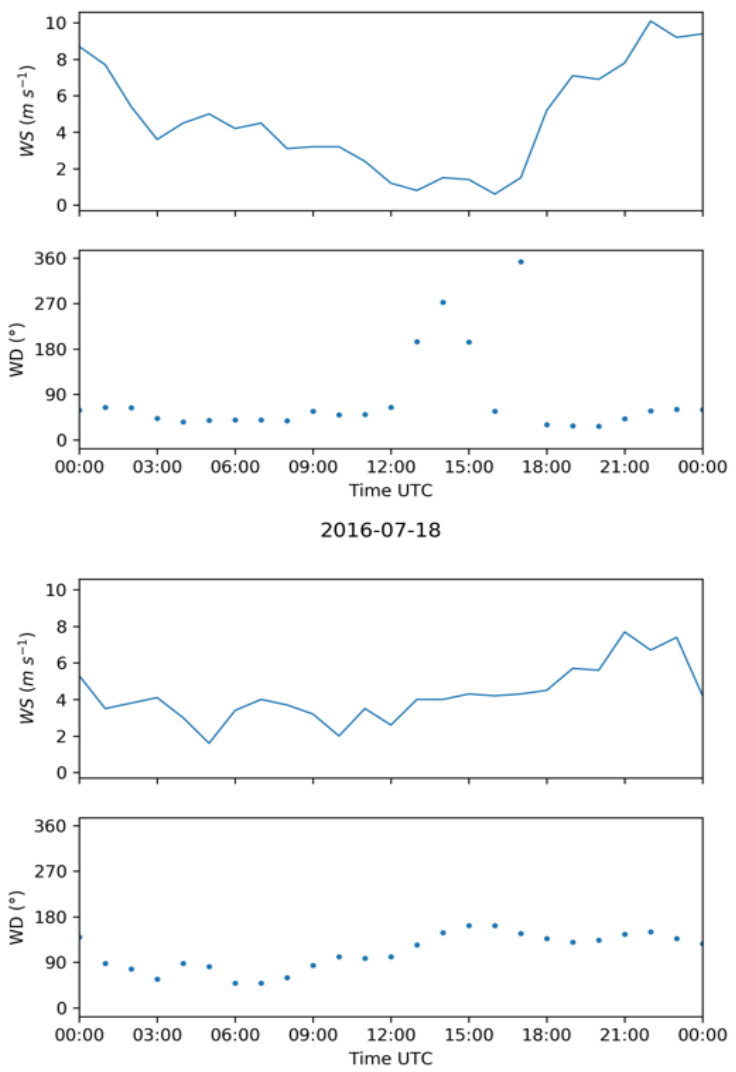

Figure S5: Daily plots of wind speed and wind direction for the days in which shrinkage is observed. 

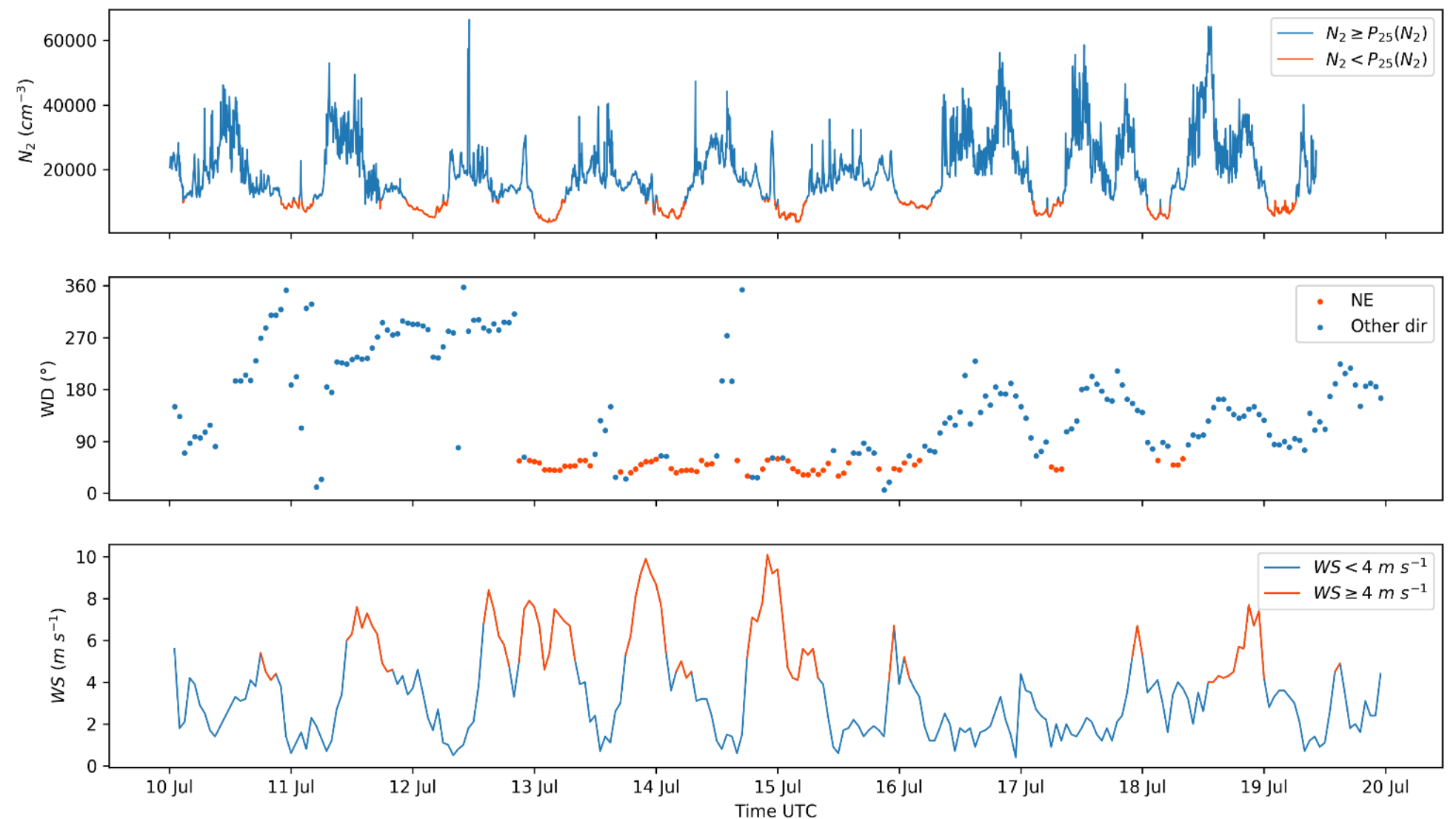

Figure S6: Concentration of particles >2 nm measured with PSM at CSIC station, wind direction and wind speed from 10 to 20 July 2016. $\mathrm{N}_{2}$ lower than 25th percentile has been highlighted, as well as NE directions and wind speeds higher than $4 \mathrm{~m} / \mathrm{s}$. 


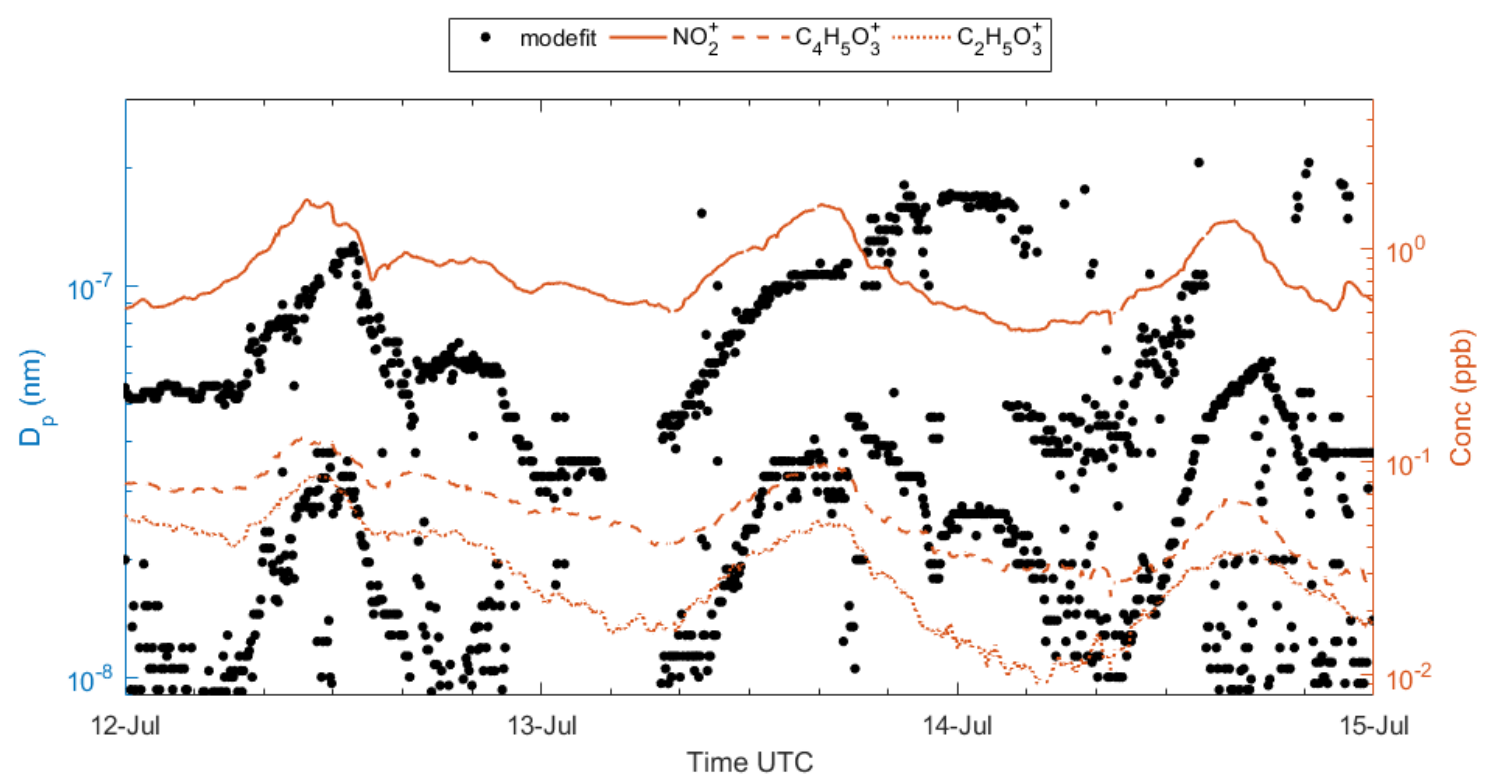

Figure S7: Temporal evolution of the log-normal fitted modes to the particle size distributions from 12 to 14 July 2016 at ISCIII and measured concentrations of three relevant VOCs. 